\title{
Effect of Divergent Selection for IgM and IgG Levels on the Change in Gene Frequency of Blood Group Systems and Blood Protein Loci in Chickens
}

\author{
Nitish SARKER, Shiho YAMAGUCHI, Masahide NISHIBORI, \\ Masaoki TSUDZUKI and Yoshio YAMAMOTO \\ Faculty of Applied Biological Science, Hiroshima University, \\ Higashi-Hiroshima-shi 739-8528, Japan
}

(Received June 18, 1999 ; Accepted August 27, 1999)

\begin{abstract}
To examine the effect of divergent selection for serum immunoglobulin M (IgM) and G (IgG) levels two pairs of chicken lines of four generations were selected. The base population from which the experiment was started composed of six lines. Serum IgM and IgG levels and changes in gene frequencies of blood groups and blood protein loci were monitored for all individuals in each generation. Selection was effective $(\mathbf{P}<0.01)$ in changing the serum IgM and IgG levels. The differences between the high immunoglobulin $M$ (HIM) and low immunoglobulin $M$ (LIM) lines as well as high immunoglobulin $\mathrm{G}$ (HIG) and low immunoglobulin G (LIG) lines became gradually larger during the process of selection. A remarkable effect of selection on the changes of gene frequencies of blood proteins was not observed. In the HIM line, gene frequency of the $B^{\mathrm{A}}$ allele increased and that of the $B^{\mathrm{G}}$ and $B^{\mathrm{N}}$ alleles decreased over the course of selection. In the LIM line, gene frequency of the $B^{\mathrm{A}}$ allele decreased and that of $B^{\mathrm{G}}$ and $B^{\mathrm{N}}$ alleles increased during the selection. Similar tendency was also observed for the $B^{\mathrm{A}}, B^{\mathrm{G}}$, and $B^{\mathrm{N}}$ alleles of HIG and LIG lines. This contrasting change in gene frequency of the $B^{\mathrm{A}}, B^{\mathrm{G}}$, and $B^{\mathrm{N}}$ alleles in the two selected lines suggest that the $B$ blood group alleles may be involved in IgM and IgG production.
\end{abstract}

Animal Science Journal 70 (6) : 421-428, 1999

Key words : Chicken, Divergent selection, Immunoglobulin, Blood groups, Blood proteins, Gene frequency

Classical breeding is still one of the best way to improve the efficiency of poultry production and to reduce the incidence of diseases, because intensive selection is expected to change gene frequencies and modify genetic variances of the selected and correlated traits. Several workers have elucidated that genetic resistance of chickens can be improved through selection for immunocompetence ${ }^{5,18,26)}$. Consequently, several lines of chickens have been developed for humoral and cell mediated immune responses. Developing line against specific antigen is the most popular and frequent approach of selection to improve the immune response and to increase the disease resistance.

Genetic resistance through improved immune response is desirable because it has the unique property of being inheritable and can improve the efficiency of resistance to various diseases. Genetic polymorphism of blood proteins in several species has been demonstrated ${ }^{10,13,19)}$. Selection for high and low antibody production to sheep erythrocytes resulted in a correlated responses for growth and reproductive traits $^{23)}$, gene frequencies at the alloantigen loci ${ }^{3,25}$, and disease resistance ${ }^{7)}$. After 10 generations of selection gene frequencies of the $B^{21}$ allele at $B$ blood group system were $79 \%$ and $0 \%$ in the high and low

Corresponding : Yoshio YAMAMOTO (fax : +81 (0) 824-24-7950, e-mail : yyama@ipc.hiroshima-u.ac.jp)

Anim. Sci. J. $70(6): 421-428,1999$ 


\section{SARKER, YAMAGUCHI, NISHIBORI, TSUDZUKI and YAMAMOTO}

lines, respectively ${ }^{20)}$. The frequency of the $B^{21}$ in the unselected control line was $11 \%{ }^{20)}$. Gene frequencies of the $B^{21}$ and $B^{13}$ were $99 \%$ and $98 \%$ in the high and low line, respectively, after 13 generations of selection ${ }^{15)}$. van der Zijpp ${ }^{25)}$ also observed changes in gene frequencies at the $B$ complex, with an increase in the frequency of the $B^{21}$ within the line selected for high antibody response.

Improved disease rcsistance may also be achieved without challenging animals with disease agents. An infectious challenge is a common form of stress encountered by growing animals and it has so far been practiced to improve the immune capacity of chickens. Regardless of the outcome, a stress response is indicated by decreased growth rate and quantitative changes in nutritional requirements. Moreover, in the antigen specific selection, the selected lines have higher antibody production against the antigens used for selection and to the relevant antigens.

Therefore, selection of chickens on the basis of serum immunoglobulin isotypes, which represents the response to a wide variety of unknown antigens, may be a useful tool in this regard. However, considerably less attention has been paid towards this technology thus far. Therefore, the purpose of the present selection program was to develop divergent chicken lines for serum IgM and IgG levels and to determine the effect of divergent selection on the changes of gene frequencies of blood proteins and blood groups in the chicken lines.

\section{Materials and Methods}

\section{Chickens}

Six chicken lines HA, LA, HG, LG, C, and GSP were used to construct the base population. From the base population, each of 10 sires and 20 dams were used to establish the parent stock, high IgG (HIG), low IgG (LIG), high IgM (HIM), and low IgM (LIM) lines, respectively. Thereafter, individual phenotypic selection was carried out within each closed line for serum IgM and IgG levels at 10 weeks of age. Details about these lines have previously described $^{21)}$. Chicks from all the lines were hatched with a single hatch and reared together under the same environmental condition. Simultaneously, at hatch- ing all the chicks were wing banded and vaccinated against Marek's disease. They were also administered Fowl Pox and Newcastle disease vaccine as per schedule. Chickens of all the lines were provided tap water and a commercial diet ad libitum.

Nomenclature of blood group alleles and blood typing

The nomenclature of the blood group alleles in the present study was given by Okada and McDermid ${ }^{17)}$, except $B^{21}$. In each generation, birds of all the lines were blood typed with specific alloantisera for blood group systems A ( $Z$, R, and P), B (A, G, N, T, and 21), $D$ ( $Q$ and $S$ ), and $E$ ( $W$ and $Y$ ) by hemagglutination at six weeks of age.

\section{Determination of blood protein loci}

The blood protein loci of all the birds in each generation were determined by horizontal starch gel and polyacrylamide gel electrophoresis. Alkaline phosphatase ( $A k p, a k p, A k p-2^{\mathrm{a}}$, and $A k p-2^{\circ}$ ) and hemoglobin $\left(H b-1^{\mathrm{A}}\right.$ and $\left.H b-1^{\mathrm{B}}\right)$ were analyzed by starch gel electrophoresis. On the other hand, esterase ( $E_{S-}$ $1^{\mathrm{A}}, E s-1^{\mathrm{B}}$, and $\left.E s-1^{\mathrm{C}}\right)$ and transferrin $\left(T f^{\mathrm{A}}, T f^{\mathrm{B}}\right.$, and $T f^{\complement}$ ) were determined by polyacrylamide gel electrophoresis.

\section{Estimation of gene frequencies}

Gene frequencies for blood proteins and blood groups were estimated by direct counting method for the loci known to have only co-dominant alleles. For the loci including recessive alleles $(A k p$ and $A k p-2$ loci), gene frequencies were calculated by the method of Ito and Kanemaki ${ }^{9}$.

\section{Quantitation of IgM and IgG}

IgM and IgG were quantitated by single radial immunodiffusion technique ${ }^{14)}$. Detail about this method has previously been described ${ }^{21)}$.

\section{Statistical analysis}

Data were analyzed using the General Linear Models procedure of SAS ${ }^{\otimes}$ software $^{22)}$. Treatment means were separated by Duncan's multiple range test.

\section{Results}

Serum IgM and IgG levels at 10 weeks of age changed considerably over the course of selection. Tables 1 and 2 demonstrate the means of $\operatorname{IgM}$ and 
Effect of Divergent Selection in Chickens

Table 1. Least squares means and standard deviation for $\operatorname{IgM}$ values $(\mathrm{mg} / \mathrm{d} l)$ in four successive generations of selection

\begin{tabular}{|c|c|c|c|c|c|c|c|c|c|}
\hline Line & Sex & $\mathrm{n}$ & First & $\mathrm{n}$ & Second & $\mathrm{n}$ & Third & $\mathbf{n}$ & Fourth \\
\hline \multirow[t]{3}{*}{ HIM } & $0^{x}$ & 33 & $66.86 \pm 9.94$ & 55 & $81.51 \pm 11.79$ & 44 & $90.42 \pm 14.42$ & 58 & $103.36 \pm 11.62$ \\
\hline & 우 & 48 & $85.65 \pm 9.85^{* *}$ & 40 & $103.02 \pm 11.99 * *$ & 52 & $97.97 \pm 13.95$ & 55 & $110.60 \pm 13.50$ \\
\hline & $\sigma^{x}+$ 우 & 81 & $76.25 \pm 11.06^{\mathrm{A}}$ & 95 & $92.26 \pm 15.92^{\mathrm{A}}$ & 96 & $94.51 \pm 14.59^{\mathrm{A}}$ & 113 & $106.98 \pm 12.52^{\mathrm{A}}$ \\
\hline \multirow[t]{3}{*}{ LIM } & $\sigma^{\pi}$ & 35 & $52.95 \pm 8.48$ & 59 & $67.98 \pm 11.19$ & 55 & $55.15 \pm 11.56$ & 55 & $58.34 \pm 9.77$ \\
\hline & 우 & 50 & $72.05 \pm 11.56^{* *}$ & 40 & $68.01 \pm 13.87$ & 54 & $54.35 \pm 12.75$ & 47 & $62.12 \pm 11.76$ \\
\hline & $\sigma^{x}+$ 우 & 85 & $62.50 \pm 11.42^{\mathrm{B}}$ & 99 & $67.99 \pm 12.18^{\mathrm{B}}$ & 109 & $54.84 \pm 11.98^{\mathrm{B}}$ & 102 & $55.23 \pm 10.80^{B}$ \\
\hline
\end{tabular}

${ }^{A}{ }^{B}$ Means of combined sex within the column with no common superscripts differ significantly $(\mathbf{P}<0.01)$.

$\mathrm{HIM}=$ high $\mathrm{IgM} ; \mathrm{LIM}=$ low $\mathrm{IgM}$.

$\mathrm{n}=$ No. of chickens used in each generation of selection.

** Sex means within the lines differ significantly $(\mathrm{P}<0.01)$.

Table 2. Least squares means and standard deviation for $\operatorname{IgG}$ values $(\mathrm{mg} / \mathrm{d} l)$ in four successive generations of selection

\begin{tabular}{|c|c|c|c|c|c|c|c|c|c|}
\hline Line & Sex & $\mathrm{n}$ & First & $\mathrm{n}$ & Second & $\mathrm{n}$ & Third & $\mathrm{n}$ & Fourth \\
\hline \multirow[t]{3}{*}{ HIG } & $\sigma^{\pi}$ & 27 & $262.42 \pm 34.59$ & 53 & $335.18 \pm 32.21$ & 46 & $358.16 \pm 36.81$ & 47 & $412.10 \pm 82.99$ \\
\hline & 우 & 34 & $279.42 \pm 34.18 * *$ & 59 & $359.65 \pm 28.87$ & 43 & $365.36 \pm 43.04$ & 62 & $417.18 \pm 80.35$ \\
\hline & $\sigma^{x}+$ 우 & 61 & $271.67 \pm 35.07^{\mathrm{A}}$ & 112 & $348.07 \pm 32.74^{\mathrm{A}}$ & 89 & $361.64 \pm 39.88^{\mathrm{A}}$ & 109 & $414.64 \pm 81.16^{A}$ \\
\hline \multirow[t]{3}{*}{ LIG } & $\pi$ & 36 & $231.50 \pm 28.79$ & 48 & $297.28 \pm 32.42$ & 59 & $285.95 \pm 33.90$ & 55 & $58.34 \pm 9.77$ \\
\hline & 우 & 36 & $245.24 \pm 24.72$ & 63 & $283.22 \pm 31.60$ & 41 & $283.85 \pm 34.76$ & 47 & $62.12 \pm 11.76$ \\
\hline & $a^{x}+$ 우 & 72 & $238.37 \pm 27.52^{\mathrm{B}}$ & 111 & $289.30 \pm 32.57^{B}$ & 100 & $285.09 \pm 34.10^{\mathrm{B}}$ & 112 & $55.23 \pm 10.80^{B}$ \\
\hline
\end{tabular}

$\mathrm{A}, \mathbf{B}$ Means of combined sex within the column with no common superscripts differ significantly $(\mathbf{P}<0.01)$.

$\mathrm{HIG}=$ high IgG $; \mathrm{LIG}=$ low IgG.

$\mathrm{n}=$ No. of chickens used in each generation of selection.

** Sex means within the lines differ significantly $(P<0.01)$.

IgG values in sexes and lines for HIM and LIM lines and HIG and LIG lines, respectively. A significant difference $(P<0.01)$ was observed between the sexes of the HIM line in the first and second generation of selection. In the LIM line, a sex difference was observed only in the first generation. Even after single generation of selection, a significant $(P<0.01)$ line difference was observed and followed in the subsequent generations. In contrast, in the $\mathrm{IgG}$ selected lines, sex difference was significant $(P<0.01)$ only in the HIG line at the first generation of selection. The HIG line had significantly $(P<0.01)$ higher IgG level than the LIG line during the selection period.

The effect of divergent selection for serum IgM on the changes of gene frequencies of blood protein loci in the HIM and LIM lines is presented in Table 3. After three generations of selection, gene frequency of the $E s-1^{\text {A }}$ slightly increased in the HIM line and decreased in the LIM line. Similar trend was also observed for the $E s-1^{\mathrm{B}}$. On the other hand, the frequency of the $E s-1^{C}$ became flat in the HIM line and slightly increased in the LIM line. Gene frequency of the $T f^{\mathrm{A}}$ became zero in both lines.

Gene frequencies of the $T f^{\mathrm{B}}$ and $T f^{\mathrm{C}}$ remain flat in both lines. However, the $T f^{\mathrm{B}}$ increased and $T f^{\mathrm{C}}$ decreased in the LIM line. Similar tendency was also observed for alkaline phosphatase loci in both lines. The frequencies of the $A k p$ and $A k p-2^{\mathrm{a}}$ decreased and 


\section{SARKER, YAMAGUCHI, NISHIBORI, TSUDZUKI and YAMAMOTO}

Table 3. Effect of divergent selection for serum IgM on the changes of gene frequencies of blood proteins in the selected chicken lines

\begin{tabular}{|c|c|c|c|c|c|c|c|c|}
\hline \multirow{2}{*}{$\begin{array}{l}\text { Blood protein } \\
\text { Loci }\end{array}$} & \multicolumn{4}{|c|}{ HIM } & \multicolumn{4}{|c|}{ LIM } \\
\hline & Go & G 1 & G2 & G 3 & Go & G 1 & $\mathrm{G} 2$ & G 3 \\
\hline \multicolumn{9}{|l|}{ Esterase } \\
\hline$E s-1^{\mathrm{A}}$ & 0.85 & 0.83 & 0.81 & 0.91 & 0.85 & 0.80 & 0.92 & 0.87 \\
\hline$E s-1^{\mathrm{B}}$ & 0.14 & 0.13 & 0.03 & 0.05 & 0.14 & 0.16 & 0.01 & 0.00 \\
\hline$E s-l^{\mathrm{C}}$ & 0.01 & 0.04 & 0.15 & 0.04 & 0.01 & 0.04 & 0.07 & 0.13 \\
\hline \multicolumn{9}{|l|}{ Transferrin } \\
\hline$T f^{\mathrm{A}}$ & 0.00 & 0.00 & 0.00 & 0.00 & 0.00 & 0.00 & 0.00 & 0.00 \\
\hline$T f^{B}$ & 0.75 & 0.73 & 0.61 & 0.76 & 0.75 & 0.72 & 0.55 & 0.54 \\
\hline$T f^{c}$ & 0.25 & 0.26 & 0.39 & 0.24 & 0.25 & 0.28 & 0.45 & 0.46 \\
\hline \multicolumn{9}{|c|}{ Alkaline Phosphatase } \\
\hline$A k p$ & 0.05 & 0.06 & 0.00 & 0.00 & 0.05 & 0.23 & 0.03 & 0.02 \\
\hline$a k p$ & 0.95 & 0.94 & 1.00 & 1.00 & $0.95^{\circ}$ & 0.17 & 0.97 & 0.98 \\
\hline$A k p-2^{\mathrm{a}}$ & 0.26 & 0.22 & 0.00 & 0.00 & 0.26 & 0.22 & 0.00 & 0.00 \\
\hline$A k p-2^{0}$ & 0.74 & 0.78 & 1.00 & 1.00 & 0.74 & 0.78 & 1.00 & 1.00 \\
\hline \multicolumn{9}{|l|}{ Hemoglobin } \\
\hline$H b-1^{\mathrm{A}}$ & 0.27 & 0.39 & 0.60 & 0.70 & 0.27 & 0.44 & 0.53 & 0.76 \\
\hline$H b-1^{\text {B }}$ & 0.73 & 0.61 & 0.40 & 0.30 & 0.73 & 0.56 & 0.47 & 0.24 \\
\hline
\end{tabular}

HIM = high IgM ; LIM = low IgM.

$\mathrm{G} 0=$ generation zero ; $\mathrm{G} 1=$ generation one ; $\mathrm{G} 2=$ generation two ; $\mathrm{G} 3$ =generation three.

the frequency of the $a k p$ and $A k p-2^{0}$ increased in both lines. Gene frequency of the $H b-I^{\mathrm{A}}$ increased and $H b-I^{\mathrm{B}}$ decreased in both lines.

The effect of divergent selection for serum IgG on the changes of gene frequency of blood proteins in the HIG and LIG lines is presented in Table 4. After three generations of selection, the $E s-1^{\mathrm{A}}$ increased in the HIG line and decreased in the LIG line. Whereas, the frequencies of the $E s-1^{\mathrm{B}}$ and $E s-1^{\mathrm{C}}$ followed the same pattern in both lines. Gene frequencies of transferrin $\left(T f^{\mathrm{A}}, T f^{\mathrm{B}}\right.$, and $\left.T f^{\mathrm{C}}\right)$, alkaline phosphatase $\left(A k p, a k p, A k p-2^{\mathrm{a}}, A k p-2^{0}\right)$, and hemoglobin ( $H b-1^{\mathrm{A}}$ and $H b-l^{\mathrm{B}}$ ) loci changed in a similar direction in both lines.

In the IgM selection, the frequencies of the $R$ and $Z$ alleles of the $A$ blood group locus decreased and the frequency of the $P$ allele increased in both lines (Table 5 ). In contrast, the frequencies of the $B^{\mathrm{A}}$ and $B^{21}$ alleles increased and the frequencies of the $B^{\mathrm{G}}$ and $B^{\mathrm{N}}$ alleles decreased in the HIM line, and it was just a reverse in the LIM line. The frequency of the $B^{\mathrm{r}}$ allele became flat in the HIM line and it was zero in the LIM line. The frequencies of the $Q$ and $S$ alleles of the $D$ locus were almost flat in the HIM line. On the other hand, the frequency of the $Q$ allele decreased and the frequency of the $S$ allele increased in the LIM line. The frequencies of the $W$ and $Y$ alleles of the $E$ locus were almost stable in both lines.

The effect of divergent selection for serum IgG on the changes of gene frequencies of blood groups in the HIG and LIG line is presented in Table 6. After four generations of selection, the frequencies of the $R$, $Z$, and $P$ alleles of the $A$ blood group locus became almost flat in both the HIG and LIG lines. However, the frequency of the $R$ allele became zero and the frequency of the $P$ allele increased in the LIG line. The frequency of the $A$ allele of the $B$ locus increased in the HIG line and decreased in the LIG line. Subsequently, the frequency of the $B^{\mathrm{G}}$ allele became lower in the HIG line and higher in the LIG line. The 


\section{Effect of Divergent Selection in Chickens}

Table 4. Effect of divergent selection for serum $\operatorname{IgG}$ on the changes of gene frequencies of blood proteins in the selected chicken lines

\begin{tabular}{|c|c|c|c|c|c|c|c|c|}
\hline \multirow{2}{*}{$\begin{array}{l}\text { Blood protein } \\
\text { Loci }\end{array}$} & \multicolumn{4}{|c|}{ HIG } & \multicolumn{4}{|c|}{ LIG } \\
\hline & G0 & G 1 & G 2 & G3 & G0 & G 1 & G 2 & G3 \\
\hline \multicolumn{9}{|l|}{ Esterase } \\
\hline$E s-1^{A}$ & 0.43 & 0.51 & 0.70 & 0.68 & 0.43 & 0.78 & 0.70 & 0.62 \\
\hline$E s-1^{B}$ & 0.56 & 0.48 & 0.07 & 0.00 & 0.56 & 0.19 & 0.08 & 0.08 \\
\hline$E s-1^{c}$ & 0.01 & 0.01 & 0.23 & 0.32 & 0.01 & 0.03 & 0.21 & 0.29 \\
\hline \multicolumn{9}{|l|}{ Transferrin } \\
\hline$T f^{a}$ & 0.00 & 0.00 & 0.00 & 0.00 & 0.00 & 0.00 & 0.00 & 0.00 \\
\hline$T f^{B}$ & 0.87 & 0.83 & 0.56 & 0.67 & 0.87 & 0.80 & 0.63 & 0.73 \\
\hline$T f^{C}$ & 0.13 & 0.17 & 0.44 & 0.33 & 0.13 & 0.19 & 0.37 & 0.27 \\
\hline \multicolumn{9}{|c|}{ Alkaline Phosphatase } \\
\hline$A k p$ & 0.34 & 0.23 & 0.01 & 0.00 & 0.34 & 0.42 & 0.00 & 0.00 \\
\hline$a k p$ & 0.66 & 0.77 & 0.99 & 1.00 & 0.66 & 0.58 & 1.00 & 1.00 \\
\hline$A k p-2^{a}$ & 0.38 & 0.25 & 0.00 & 0.00 & 0.38 & 0.00 & 0.00 & 0.00 \\
\hline$A k p-2^{0}$ & 0.62 & 0.75 & 1.00 & 1.00 & 0.62 & 1.00 & 1.00 & 1.00 \\
\hline \multicolumn{9}{|l|}{ Hemoglobin } \\
\hline$H b-1^{A}$ & 0.25 & 0.32 & 0.65 & 0.68 & 0.25 & 0.39 & 0.40 & 0.64 \\
\hline$H b-1^{B}$ & 0.75 & 0.68 & 0.35 & 0.32 & 0.75 & 0.61 & 0.60 & 0.36 \\
\hline
\end{tabular}

$\mathrm{HIG}=$ high $\mathrm{IgG} ; \mathrm{LIG}=$ low IgG.

$\mathrm{G} 0=$ generation zero; $\mathrm{G} 1=$ generation one $; \mathrm{G} 2=$ generation two $\mathrm{G} 3=$ generation three.

frequency of the $B^{\mathrm{N}}$ allele became zero in the HIG line, but it was almost fiat in the LIG line. Similarly, the frequency of the $Q$ allele increased and the frequency of the $S$ allele decreased a little bit in both lines. The frequency of $W$ allele decreased and the frequency of the $Y$ allele increased in the HIG line, reversibly, the frequency of the $W$ allele increased and the frequency of the $Y$ allele decreased in the LIG line.

\section{Discussion}

In this study, divergent selection for serum IgM and IgG levels resulted in a significant line differences during the course of selection. In both the low lines of LIM and LIG, selection response seemed not significant between generations, though it might be mainly caused by environmental variation at each generations, it is difficult to clear the environmental effects because of lack of control population. However, several more generations of selection may be necessary to obtain constant differences between the selected lines. The female chickens generally had higher serum IgM and IgG levels than the males. This result was in agreement with the result of Letiner et al. ${ }^{12)}$. Similar results were also reported in humans and mice ${ }^{1,2,8,16)}$. From this result it is postulated that sex hormones may have modulated the immune response.

Although there are some reports on genetic control of blood proteins in several species including chickens ${ }^{10,13,19)}$ however, in this study, a remarkable changes in gene frequencies of blood proteins in both pairs of selected lines were not observed. Although the reason behind this is not clear, this discrepancy may be due to the non association of the particular genes of blood proteins in the $\mathrm{IgM}$ and $\mathrm{IgG}$ production.

In the HIM line, the frequency of the $B^{\mathrm{A}}$ allele increased from 0.28 to 0.44 and the frequency of the $B^{\mathrm{G}}$ and $B^{\mathrm{N}}$ decreased from 0.33 to 0.21 and 0.12 to 0.00 , respectively. In the LIM line, the frequency of

Anim. Sci. J. 70 (6) : 421-428, 1999 
SARKER, YAMAGUCHI, NISHIBORI, TSUDZUKI and YAMAMOTO

Table 5. Effect of divergent selection for serum IgM on the changes of gene frequencies of blood groups in the selected chicken lines

\begin{tabular}{|c|c|c|c|c|c|c|c|c|c|c|c|}
\hline \multirow{2}{*}{$\begin{array}{l}\text { Blood } \\
\text { groups }\end{array}$} & \multirow{2}{*}{ Alleles } & \multicolumn{5}{|c|}{ HIM } & \multicolumn{5}{|c|}{ LIM } \\
\hline & & G 0 & G 1 & G2 & G 3 & G 4 & Go & G 1 & G 2 & G 3 & G 4 \\
\hline \multirow[t]{3}{*}{$A$} & $R$ & 0.01 & 0.15 & 0.08 & 0.05 & 0.02 & 0.01 & 0.02 & 0.00 & 0.00 & 0.00 \\
\hline & $Z$ & 0.51 & 0.43 & 0.35 & 0.37 & 0.34 & 0.51 & 0.55 & 0.49 & 0.47 & 0.20 \\
\hline & $P$ & 0.48 & 0.42 & 0.57 & 0.58 & 0.64 & 0.48 & 0.43 & 0.51 & 0.53 & 0.80 \\
\hline \multirow[t]{5}{*}{$B$} & $A$ & 0.28 & 0.34 & 0.44 & 0.43 & 0.44 & 0.28 & 0.21 & 0.08 & 0.00 & 0.00 \\
\hline & $G$ & 0.33 & 0.31 & 0.24 & 0.23 & 0.21 & 0.33 & 0.42 & 0.57 & 0.69 & 0.71 \\
\hline & $N$ & 0.12 & 0.04 & 0.00 & 0.00 & 0.00 & 0.12 & 0.17 & 0.21 & 0.29 & 0.23 \\
\hline & $T$ & 0.03 & 0.13 & 0.13 & 0.23 & 0.08 & 0.03 & 0.03 & 0.04 & 0.00 & 0.00 \\
\hline & 21 & 0.23 & 0.19 & 0.22 & 0.11 & 0.27 & 0.23 & 0.17 & 0.11 & 0.02 & 0.06 \\
\hline \multirow[t]{2}{*}{$D$} & $Q$ & 0.58 & 0.56 & 0.70 & 0.79 & 0.54 & 0.58 & 0.45 & 0.37 & 0.47 & 0.24 \\
\hline & $S$ & 0.42 & 0.44 & 0.30 & 0.21 & 0.16 & 0.42 & 0.55 & 0.63 & 0.53 & 0.79 \\
\hline \multirow[t]{2}{*}{$E$} & $W$ & 0.40 & 0.49 & 0.48 & $0.4 \%$ & 0.53 & 0.40 & 0.44 & 0.51 & 0.57 & 0.59 \\
\hline & $Y$ & 0.60 & 0.51 & 0.52 & 0.53 & 0.47 & 0.60 & 0.56 & 0.49 & 0.43 & 0.41 \\
\hline
\end{tabular}

HIM= high IgM ; LIM = low IgM.

$\mathrm{G} 0=$ generation zero; $\mathrm{G} 1=$ generation one ; $\mathrm{G} 2=$ generation two; $\mathrm{G} 3=$ generation three ; $\mathrm{G} 4=$ generation four.

Table 6. Effect of divergent selection for serum IgG on the changes of gene frequencies of blood groups in the selected chicken lines

\begin{tabular}{|c|c|c|c|c|c|c|c|c|c|c|c|}
\hline \multirow{2}{*}{$\begin{array}{l}\text { Blood } \\
\text { groups }\end{array}$} & \multirow{2}{*}{ Alleles } & \multicolumn{5}{|c|}{ HIG } & \multicolumn{5}{|c|}{ LIG } \\
\hline & & G0 & G 1 & G 2 & G 3 & G 4 & Go & G 1 & G 2 & G 3 & G 4 \\
\hline \multirow[t]{3}{*}{$A$} & $R$ & 0.01 & 0.05 & 0.03 & 0.02 & 0.01 & 0.01 & 0.11 & 0.01 & 0.05 & 0.00 \\
\hline & $Z$ & 0.53 & 0.43 & 0.49 & 0.57 & 0.46 & 0.53 & 0.45 & 0.34 & 0.32 & 0.37 \\
\hline & $P$ & 0.46 & 0.52 & 0.47 & 0.41 & 0.52 & 0.46 & 0.44 & 0.64 & 0.64 & 0.63 \\
\hline \multirow[t]{5}{*}{$B$} & $A$ & 0.25 & 0.26 & 0.34 & 0.49 & 0.49 & 0.25 & 0.18 & 0.22 & 0.14 & 0.09 \\
\hline & $G$ & 0.32 & 0.33 & 0.26 & 0.21 & 0.19 & 0.32 & 0.34 & 0.33 & 0.36 & 0.41 \\
\hline & $N$ & 0.13 & 0.09 & 0.08 & 0.67 & 0.00 & 0.13 & 0.21 & 0.20 & 0.27 & 0.20 \\
\hline & $T$ & 0.13 & 0.09 & 0.10 & 0.08 & 0.09 & 0.03 & 0.07 & 0.11 & 0.11 & 0.02 \\
\hline & 21 & 0.26 & 0.27 & 0.21 & 0.15 & 0.23 & 0.26 & 0.19 & 0.14 & 0.12 & 0.28 \\
\hline \multirow[t]{2}{*}{$D$} & $Q$ & 0.61 & 0.57 & 0.51 & 0.46 & 0.72 & 0.61 & 0.41 & 0.54 & 0.88 & 0.86 \\
\hline & $S$ & 0.39 & 0.43 & 0.49 & 0.55 & 0.28 & 0.39 & 0.59 & 0.46 & 0.13 & 0.14 \\
\hline \multirow[t]{2}{*}{$E$} & $W$ & 0.39 & 0.44 & 0.40 & 0.20 & 0.18 & 0.39 & 0.43 & 0.48 & 0.52 & 0.62 \\
\hline & $Y$ & 0.61 & 0.56 & 0.60 & 0.80 & 0.82 & 0.61 & 0.57 & 0.52 & 0.48 & 0.38 \\
\hline
\end{tabular}

$\mathrm{HIG}=$ high IgG $; \mathrm{LIG}=$ low IgG.

$\mathrm{G} 0=$ generation zero; $\mathrm{G} 1=$ generation one ; $\mathrm{G} 2=$ generation two $\mathrm{G} 3=$ generation three ; $\mathrm{G} 4=$ generation four. 
the $B^{\mathrm{A}}$ allele decreased from 0.28 to 0.00 and the frequencies of the $B^{\mathrm{G}}$ and $B^{\mathrm{N}}$ allele increased from 0.33 to 0.71 and 0.12 to 0.23 , respectively.

In the HIG line, gene frequency of the $B^{\mathrm{A}}$ allele increased from 0.25 to 0.49 during the period of selection and gene frequencies of the $B^{\mathrm{G}}$ and $B^{\mathrm{N}}$ alleles decreased from 0.32 to 0.19 and from 0.13 to 0.00 , respectively. In contrast, in the LIG line, gene frequency of the $B^{\mathrm{A}}$ allele decreased from 0.25 to 0.09 and the frequencies of the $B^{G}$ and $B^{N}$ alleles increased from 0.32 to 0.41 and 0.13 to 0.20 , respectively. This contrasting changes in gene frequency of the $B^{\mathrm{A}}$ and $B^{\mathrm{G}}$ in the two selected lines suggest that these alleles may be associated with immunoglobulin production. Although comparable data are not available in the literature, similar results were demonstrated ${ }^{4)}$. This result suggest that selection of chickens for serum immunoglobulin isotypes may change the frequency of the $B$ haplotypes in each line. The present study concurs with the study by Simonsen et al. ${ }^{24}$, Gavora et $a l_{.}{ }^{6)}$, and Lamont et al. ${ }^{11)}$ that the predominant $B$ haplotypes responded differently to the selection pressure applied. Lamont et al. ${ }^{11)}$ found that the frequency of the $B^{2}$ alleles significantly increased at the expense of the $B^{13}$ in chicken lines that were selected for egg production and feed efficiency, Gavora et al. ${ }^{6)}$ found that the frequency of the $B^{19}$ reduced in the MD-resistance selected strain, but about the same in control and production selected strains. The frequency of the $B^{21}$ and the combined frequency of the $B^{2}$ and $B^{21}$ increased in Marek's disease resistance strains which support our results ${ }^{6)}$. On the other hand, a strong association was not observed in the IgM and IgG pairs of selected lines for alleles of other blood groups reflecting that these alleles may not have remarkable influence on the IgM and IgG production.

This study suggests that simultaneous selection for serum immunoglobulin isotypes is possible and selection of chickens for serum immunoglobulin isotypes changed the frequency of the $B$ haplotypes in each line. Moreover, we believe that this research has contributed to the understanding of the genetic parameters that can be used in the preceding experiments.

\section{References}

1) Ahmed AS, Penhale W, Talal N. Sex hormones, immune responses, and autoimmune diseases. American Journal of Pathology, 125 : 531-551. 1985.

2) Astorquiza MI, Cisternas C, Leal X. Sex-dependent differences in the $\mathrm{IgG}$ response modulated by phytohemagglutinin. Immunology Letter, 16:27-30. 1987.

3) Dunnington EA, Briles RW, Briles WE, Gross WB, Siegcl PB. Allelic frequencies in eight alloantigen systems of chickens selected for high or low antibody response to sheep red blood cells. Poultry Science, 63 : 1470-1472. 1984.

4) Dunnington EA, Siegel PB. Long term divergent selection for eight-week body weight in White Plymouth Rock chickens. Poultry Science, 75:1168-1179. 1996.

5) Gavora JS, Spencer JL. Breeding for immune responsiveness and disease resistance. Animal Blood Groups and Biochemical Genetics, $14: 159-180$. 1983.

6) Gavora JS, Simonsen M, Spencer L, Fairfull RW, Gowe RS. Changes in the frequency of major histocompatibility haplotypes in chickens under selection for both high egg production and resistance to Marek's disease. Tijdschr Zuchtungsbiology, 103 : 218-226. 1986

7) Gross WG, Siegel PB, Hall RW, Domermuth $\mathrm{CH}$, DuBoise RT. Production and persistance of antibodies in chickens to sheep erythrocytes. Resistance to infectious diseases. Poultry Science, $59: 205-210$. 1980.

8) Grossman CJ. Possible underlying mechanisms of sexual dimorphism in the immune response, fact and hypothesis. Journal of Steroid Biochemistry, 34 : 241251. 1989

9) Ito S, Kanemaki M. A computer-aided procedure for finding probable phenotype distribution in bovine $B$ blood group system. Japanese Journal of Zootechnical Science, 58 : 591-603. 1987.

10) Kumar RJ, Christensen K, Andersen E, Gahne B. Frequencies of transferrin types in various breeds of domestic dogs. Animal Blood Groups and Biochemical Genetics, $12: 79-88.1980$.

11) Lamont SJ, Hou YH, Young BM, Nordskog AW. Research note : differences in major histocompatibility complex gene frequencies associated with feed efficiency and laying performance. Poultry Science, 66 
: 1064-66. 1987.

12) Letiner G, Uni Z, Cahaner A, Gutman M, Heller ED. Replicated divergent selection of broiler chickens for high or low early antibody response to Escherichia coli vaccination. Poultry Science, 71 : 2737. 1992.

13) Maeda Y, Washburn KW, Marks HL. Protein polymorphism in quail population selected for large body size. Animal Blood Groups and Biochemical Genetics, $11: 251-260.1980$.

14) Mancini G, Carbonara A, Hermans JF. Immunochemical quantitation of antigens by single radial immunodiffusion. Immunochemistry, 2:235-239. 1965.

15) Martin A, Dunnington EA, Gross WB, Briles WE, Briles RW, Siegel PB. Production traits and alloantigen systems in lines of chicken selected for high or low antibody responses to shcep erythrocytes. Poultry Science, $69: 871-878.1990$.

16) Nelson JL, Steinberg AD. Sex steroids, autoimmunity and autoimmune diseases. In : Hormone Immunity. Chapter 6. (Berczi I, Kovacs K eds.) 93119. MTP press. Belgium. 1987.

17) Okada I, McDermid EM. Some aspects of international comparison test for blood grouping in chickens. Japanese Journal of Zootechnical Science, 41 : 319-325. 1970.

18) Okada I, Yamamoto Y. Immunocompetences and Marek's disease resistance in three pairs of chicken lines selected for different immunological characters. Poultry Science, 66: 769-773. 1987
19) Pepin L, Nguyen TC. Blood groups and protein polymorphisms in five goat breeds. Animal Genetics, 25. 333-336. 1994.

20) Pinard MH, Jauss LLG, Maatmann R, Noordhuizen JPTM, van der Zijpp AJ. Effect of divergent selection for immune responsiveness and of major histocompatibility complex on resistance to Marek's disease in chickens. Poultry Science, $72: 391-402$. 1993.

21) Sarker N, Tsudzuki M, Nishibori M, Yamamoto $Y$. Direct and correlated responses to selection for serum immunoglobulin $M$ and $G$ levels in chickens. Poultry Science, $78: 1-7.1999$.

22) SAS Institute. SAS User's Guide : Statistics. Version 5 Edition. SAS Institute Inc., Cary, NC. 1985.

23) Siegel PB, Gross WB, Cherry JA. Correlated responses of chickens to selection for production of antibodies to sheep erythrocytes. Animal Blood Groups and Biochemical Genetics, $13: 291-297$. 1982.

24) Simonsen M, Kolstad N, Edfors-Lilja I, Liljedahl E, Sorenson P. Major histocompatability genes in laying hens. American Journal of Reproductive Immunology, 2 : 148-152. 1982.

25) van der Zijpp AJ. Genetic aspects of disease resistance in farm animals. Tijdschr Diergeneeskd, 112 : 927-933. 1987

26) Warner CM, Meeker DL, Rothschild MF. Genetic control of immune responsiveness : A review of its use as a tool for selection for disease resistance. Journal of Animal Science, 64 : 159-180, 1987. 